\title{
Isolation And Identification of Pseudomonas aeruginosa from Some Clinical And Environmental Samples And Study Its Activity for The Production of Pyocyanin And Protease
}

\author{
Nazar Mohammed Hassan Al-mamari \\ University of Mosul \\ College of Education for Pure Science \\ Biology Department \\ Nazar.almamary@yahoo.com \\ DOI: $\underline{10.33899 / \text { edusj.1970.163328 }}$
}

Received

25/ $10 / 2018$

\author{
Adeba Younes Sharif Al-Numa'an \\ University of Mosul \\ College of Science \\ Biology Department \\ Shareefadeeba@yahoo.com
}

\section{Accepted \\ $03 / 12$ / 2018}

\begin{abstract}
The study includes isolation and identification of Pseudomonas aeruginosa from different sources as (90) samples were collected during a period from November (2017) to February (2018), including (wounds, suckers, urine, drinking water), Twinty five isolates of Pseudomonas aeruginosa were identified depending on morphological and biochemical tests at a rate of $(27.77 \%)$ from total samples including (13) isolates from suckers used for sucking solutions from respiratory tract, (7) isolates from wounds, (3) isolates from urine and (2) isolates from drinking water. The isolates from sucker formed the highest rate reached $(14.44 \%)$ of total samples and (52\%) of total Pseudomonas aeruginosa isolates, whereas the lowest rate was from drinking water $(2.22 \%)$ of total samples and (8\%) of total Pseudomonas aeruginosa isolates. The results showed that $(92 \%)$ of total isolates were pyocyanin producer on King A agar medium, It was also found that all isolates of this bacteria have the ability to produce protease.
\end{abstract}

Key words: Pseudomonas aeruginosa, Pyocyanin, Protease. 


\section{عزل وتثخيص جرثومة Pseudomonas aeruginosa من بعض العينات السريرية والبيئية ودراسة فعاليتها لإنتاج صبغة البايوسيانين وانزيم البروتييز}

$$
\begin{aligned}
& \text { أديبه يونس شريف النعمان } \\
& \text { جامعة الموصل } \\
& \text { كلية العلوم } \\
& \text { قسم علوم الحياة }
\end{aligned}
$$

Shareefadeeba@yahoo.com

DOI: $10.33899 /$ edusj.1970.163328

$$
\text { كزار محمد حسن المعمارية التربية للعلوم الموصل }
$$

Nazar.almamary@yahoo.com

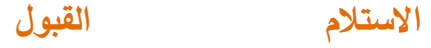

$$
\begin{aligned}
& 2018 \text { / } 12 \text { / } 03 \quad 2018 \text { / } 10 \text { / } 25
\end{aligned}
$$

\section{الخلاصة}

تضمنت الدراسة عزل وتثخيص جرثومة الزائفة الزنجارية Pseudomonas aeruginosa من

مصادر مختلفة إذ جُمعت (90) عينة في الفترة بين شهر تشرين الثاني (2017) حتى نهاية شهر شباط (2018) شمِلت (الجروح، جهاز سحب السوائل من الجهاز التتفسي Sucker، الادرار، مياه الثرب)، تم الحصول على (25) عُزلة جرثومية تعود لجرثومة الزائفة الزنجارية والتي تم تشخيصها إعتماداً على الصفات المظهرية والإختبارات الكيموحيوية وبنسبة عزل بلغت (27.77\%) من المجموع الكلي للعينات توزعت بواقع (13) عزلة من أجهزة سحب السوائل من الجهاز التتفي، (7) عزلات من الجروح، (3) عزلات من الإدرار وعزلتان من مياه الثرب. شكلت عزلات جرثومة الزائفة الزنجارية المعزولة من أجهزة سحب السوائل من الجهاز التتفسي أعلى نسبة إذ بلغت (14.44\%) من المجموع الكلي للعينات و(52\%) من مجموع عزلات جرثومة الزائفة الزنجارية فيما كانت اقل نسبة عزل لهذه الجرثومة من عينات مياه الشرب وبنسبة (2.22\%) من المجموع الكلي للعينات و (8\%) من مجموع عزلات هذه الجرثومة. ووجد أن نسبة (92\%) من المجموع الكلي لعزلات هذٍِ الجرثومة كانت مُنتجة للصبغة الزرقاء المخضرة Pyocyanin على وسط اكار King A. اضافةً الى أن جميع العزلات لهذه الجرثومة اظهرت قابلية على إنتاج إنزيم البروتييز. الكلمات المفتاحية: جرثومة الزائفة الزنجارية، صبغة البايوسيانين، انزيم البروتييز 


\section{Introduction المقدمة}

تُعد جرثومة الزائفة الزنجارية Pseudomonas aeruginosa من الممرضات الانتهازية Opportunistic pathogen الجرثومة القدرة على العيش في بيئات متتوعة لإحتياجها متطلبات تغذوية قليلة ومقاومتها للمضادات الحيوية، فهى تمتلك قابلية فائقة على التكيف في البيئات غير المناسبة لنمو الاحياء المجهية والتي قد تكون معدومة المغذيات تقريباً(1). ولها قدرة عالية في إحداث العديد من الإصابات للإنسان إذ تُعد أكثر الممرضات شيوعاً وتشكل خطراً حقيقياً على المرضى الراقدين في المستشفيات بشكل خاص كالاشخاص المصابين بالحروق والجروح ومرضى السرطان وزراعة الاعضاء ومرضى نقص المناعة فهى إحدى اهم انواع الجراثيم المسببة لما

يعرف بعدوى المستشفيات Nosocomial infection (2)

يعتدد الطيف الواسع من الامراض التي تُشبها الجرثومة على إمتلاكها العديد من عوامل الضراوة، منها المقترن بالخلية كالاسواط Flagella والأهداب من نوع Pili IV التي تستعملها في عملية الالتصاق على الخلايا الظهارية والسطوح الحرة والاستيطان ومن ثم تكوين الغشاء الحيوي Biofilm الذي هو في الاصل عبارة عن متعدد سكريات خارجي مخاطي Mucoid exopolysaccharide يسمى Alginate تفرزه سلالات هذه الجرثومة وخاصةً المعزولة من الإفرازات التنفسية لمرضى التليف الكيسي Cystic fibrosis كعامل اخر من عوامل الضراوة المرتبطة بالخلية، فضلاً عن متعدد السكريات الدهني Lipopolysaccharides، كما تمتلك القدرة على غزو الانسجة الموضعية وتحطيمها ولها ميل لغزو مجرى الدم وإحداث الامراض الجهازية Systemic disease البلعمة Phagocytosis والدفاعات المناعية للمضيف Host immune defenses وإفرازها للإنزيمات الخارجية والذيفانات مثل انزيمات Coagulase ، Elastase ، protease، Lipase ،hemolysin ، (Phosphatase alkaline ،DNase ،gelatinase الحديد Siderphore التي تُعد عوامل ضراوة خارجية تعمل على تحطيم الحواجز الفيزيائية وتشارك في الغزو الجرثومي (4)، يُعد انزيم البروتييز من أهم عوامل الضراوة لهذه الجرثومة كونه يعمل على تحطيم الانسجة عن طريق تحليل المواد البروتينية خاصة في الانسجة العضلية، وفصل الالتحام الوثيق بين الخلايا الظهارية، كما يعمل على تحليل Fibronectin وتثبيط Q-antiproteinase ويعمل على تحفيز إفراز المخاط Mucus (5). إضافة الى الصبغات التي لاتقل أهمية عن عوامل الضراوة الخارجية الاخرى، إذ تُتجج جرثومة الزوائف الزنجارية العديد من الصبغات أهمها صبغة البايوسيانين Pyocyanin pigment ذات اللون الازرق المخضر، والتي تُلاحظ على سطح الطبق الزرعي ويُشار لها بالقيح الأزرق Blue pus إذ تُميز الإصابات القيحية الناتجة بفعل هذه الجرثومة، فضلا عن وجود صبغات أخرى منها صبغة البايوفردين Pyoverdin pigment ذات اللون الاصفر المخضر، تتألق هذه الصبغة عند تعريضها للأشعة فوق البنفجية، وصبغة البايوميلانين Pyomelanin pigment 
صبغة البايوسيانين ناتجاً لعمليات الايض الثانوي، وهى تتنمي لعائلة الفينازينات لإحتوائها على نواة الفينازين، وفضلاً عن كونها عامل ضراوة فهى تعمل كجزئة إثارة إستشعار حيوي، تشارك في مجموعة متتوعة من الأنشطة الحيوية الهامة بما في ذلك التعبير الجيني، وهى تُحافظ على حيوية الخلايا الجرثومية المنتجة لها وتدعم تشكيل الغشاء الحيوي، وتتميز بفعاليتها المضادة للجراثيم والفطريات (7).

\section{المواد وطرائق العمل Materials and Methods}

\section{1- جمع العينات Collection of Specimens}

جُمعت (90) عينة شملت (30) عينة لمسحات الجروح المتقيحة، و(30) عينة لمسحات من عدة أجهزة لسحب السوائل من الجهاز التتفسي الـ Sucker، و(20) عينة من إدرار المرضى المصابين بأخماج القناة American Public البولية، كما جُمعت (10) عينات من مياه الثرب بإعتماد طريقة رابطة الصحة الأميركية Health Association (APHA) على (0.4) مل من محلول ثايوسلفات الصوديوم بتركيز (10\%) لإزالة تاثير الكلور المتبقي في عينة الماء، جُمعت العينات عن طريق تتظيف الحنفية التي تُجهز المنزل بماء الإسالة الرئيسي بصورة جيدة من المواد المتكلسة وعُقت بطريقة التلهيب الكحولي ثم فتحت الحنفية على سعتها للتخلص من المياه الراكدة ثم مُلئت القنينة المعقدة وذلك بفتح الغطاء قرب الحنفية وملئت بسرعة، ونقلت العينات الى المختبر خلال مدة زمنية لاتجاوز ثلاث ساعات لغرض عزل الجرثومة المستهدفة (8). جُمعت العينات المرضية من الاطفال والبالغين ومن الذكور والإناث من مستشفى السلام التعليمي والمستشفى الجمهوري العام ومستشفى ابن سينا التعليمي ومستشفى ابن الاثير للاطفال ومستثفى الحميات ومجمع الرازي الطبي التخصصي في الموصل، اما عينات المياه فقد جُمعت من بعض احياء مدينة الموصل في الفترة مابين تشرين الثاني (2017) حتى نهاية شباط

Cultural Media الاوساط الزرعية 2-2

أُستُعملت الاوساط الغذائية الأتية:

\section{2-1-2 - 2- الاوساط الجاهزة:}

وسط الاكار المغذي Nutrient agar، وسط المرق المغذي Nutrient broth ، وسط اكار

الماكونكي MacConkey agar ، وسط مرق نقيع القلب والدماغ Brain-Heart infusion broth،

وسط ماء البيتون Pepton water ، وسط آكار ثلاثي السكر والحديد Triple sugar iron

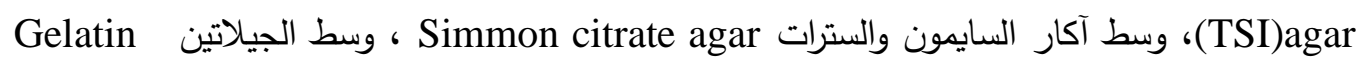
Medium والتي جُهزت من قبل شركة (LAB M limited) الانكليزية. 
2-2-2 - الاوساط الزرعية المحضرة:

1- 1 وسط آكار الدم Blood agar medium

2- وسط آكار السترمايد Cetrimide agar

3ing A وسط آكار

King B وسط آكار

5kimmed milk agar وسط آكار حليب الفرز

6otility medium وسط آكار الحركة (وسط شبه الصلب)

7rea agar medium وسط آكار اليوريا

8- وسط ماء البيتون والكلوكوز والفوسفيت Glucose phosphate peptone water medium

$$
\text { حُضرت جميع الاوساط اعلاه حسب ماورد في (9) و(10). }
$$

Pseudo. aeruginosa 3زعل جرثومة الزائفة الزنجاريـاية

لُقحت مسحات الجروح ومسحات جهاز سحب السوائل الـ Sucker مباشرةً على وسط آكار الدم ووسط آكار الماكونكي، اما عينات الإدرار فقد اخذ (0.1) مل من العينة الى وسط مرق نقيع القلب والدماغ وحُضنت بدرجة حرارة (37) م مولمدة (24) ساعة ثم نُقلت حملة بواسطة العروة المعقمة من المزرعة السائلة الى وسط آكار الدم ووسط آكار الماكونكي ولقحت بطريقة التخطيط وحُضنت بدرجة حراة (37)ْم لمدة (24) ساعة، ثم نُقلت المستعمرات التي اظهرت صفات مزرعية مثابهة لصفات الجرثومة قيد الدراسة الى وسط آكار السترمايد ووسط Pseudo. وحضنت بدرجة حرارة (37) م م ولمدة (24) ساعة للتأكد من ان العزلات تعود الى جرثومة King A .aeruginosa

اما عن عزل الجرثومة من مياه الثرب فقد استعملت طريقة الترشيح الغشائي إذ رُشحت عينة الماء باستعمال اوراق ترشيح نوع Cellulose nitrate filter ذات ثقوب بقطر (0.45) مايكروميتر، وباستعمال قمع بوخنر Buchner funnel تحت ضغط مخلخل باستعمال جهاز تفريخ الضغط Vacuum pump إذ تم ترشيح (100) مل من عينة ماء الحنفية خلال ورقة الترشيح تحت ظروف التعقيم، ثم نُقلت ورقة الترشيح بإستعمال ملقط معقم الى سطح الوسط الغذائي الإنتخابي آكار السترمايد المحضر والمعقم والمصبوب في اطباق بتري، ثم حُضنت الأطباق عند درجة حراة (37) مه إذ تنتشر المواد الغذائية للوسط خلال ثقوب ورقة الترشيح لتصل الى الجراثيم المحتجزة على سطح ورقة الترشيح، وبعد (18-24) ساعة من التحضين تم ملاحظة مستعمرات جرثومة الزائفة الزنجارية في حال وجودها في العينة نامية على سطح ورقة الترشيح والتي يمكن التعرف عليها وتشخيصها من خلال ملاحظة إنتاجها لصبغة البايوسيانين الزرقاء المخضرة في حال كون العزلة منتجة للصبغة (11). 
4- التشخيص Identification

$$
\text { 4ُ-1-1-4 الصفات العزلات الجرثومية إعتماداً على الصفات الزرعية والمجهرية والإختبارات الكيموحيوية. }
$$

ذُرست الصفات الزرعية لعزلات جرثومة الزوائف الزنجارية بإختبار قدرتها على النمو في وسط آكار الماكونكي ووسط آكار الدم وكذلك على الوسط الانتخابي وسط آكار السترمايد، والوسط المعزز لإنتاج صبغة البايوسيانين King A، وذلك لتشخيص صفاتها المزرعية من حيث شكل ولون المستعمرات وطبيعة تحلل الدم (12). تم انتخاب المستعمرات النامية على وسطي آكار الماكونكي ووسط آكار الدم والتي تتصف بكونها غير مخمرة لسكر اللاكتوز والمحلة للدم تحلاً كاملاً من نوع م-hemolysis والتي انتجت الصبغة على وسط King A الفحص المجري والإختبارات الكيموحيوية الأتية.

2-4-(الفحص المجهري

أجري الفحص المجري لخلايا العزلات الجرثومية النامية وذلك بنقل جزء من مستعمرة فتية بواسطة العروة المعقدة ومُزجت مع قطرة من الماء المقطر على سطح شريحة زجاجية نظيفة ثم نُشرت على سطح الشريحة وتركت لتجف وثُبتت بالحرارة ثم صُبتت بطريقة كرام وفُحصت تحت المجر لملاحظة شكل الخلايا الجرثومية

وطبيعة تفاعلها مع صبغة كرام (9). 3-4 -3 الإختبارات الكيموحيوية

1-مجموعة إختبارات IMViC والتي تشمل (اختبار انتاج الاندول Indol production test , اختبار المثيل الاحمر Methyl red test, اختبار فوكس بروسكاور Voges-Proskauer test , اختبار استهلاك السترات .(Citrate utilization test Oxidase Test إختبار الأوكسديز 3- إختبار الكتاليز Catalase test 4- إختبار الكثف عن انزيم محلل الدم Detection of haemolytic activity 5rease test إختبار إنتاج أنزيم اليورييز

6otility test إختبار الحركة 7-7 إختبار النمو على وسط آكار السترمايد Grwth on Cetrimide agar 8- إختبار تميع الجيلاتين 9rowth on Triple Sugar Iron (TSI) agar إختبار النمو على وسط آكار ثلاثي السكر والحديد test 10- إختبار قابلية النمو بدرجات الحرارة (4) م و (42)ْ 


$$
\text { أُجربت جميع الاختبارات اعلاه حسب ماورد في (9) و(10). }
$$

5- إختبار قابلية الجراثيم المعزولة لإنتاج الصبغات على وسطي King A و King لُقحت اطباق من وسطي King A و بطريقة التخطيط بمستعمرات فتية من الجراثيم قيد الدراسة، وحُضنت بدرجة حرارة (37)م ولمدة (24-72) ساعة ولوحظت قدرة الجراثيم على إنتاج الصبغات (13) .

6- إختبار قابلية الجراثيم المعزولة لإنتاج انزيم البروتييز Protease production test استُعمل هذا الإختبار للتحري عن قابلية الجراثيم على إنتاج انزيم البروتييز إذ لُقح وسط آكار حليب الفرز بعزلات جرثومية نقية وبشكل خط في الوسط الزرعي، وخُضنت الاطباق عند درجة حرارة (37)ْم ولمدة (24) ساعة، وعُدَّ تكّون منطقة شفافة حول خط الزرع دليلاً على قدرة الجرثومة على إنتاج

$$
\text { انزيم البروتيز وحصول تحلل مائي للكازائين وعدّت النتيجة موجبة (10). }
$$

\section{Results and Discussion}

1 Pseudo.aeruginosa

تم الحصول على (25) عزلة جرثومية تعود للنوع Pseudo.aeruginosa من مجموع (90) عينة جُمعت من مصادر مختلفة شمِلت جروح متقيحة (30) عينة، أجهزة سحب السوائل من الجهاز التتفسي الـ Sucker (30) عينة، إدرار لمرضى مصابين باخماج القناة البولية (20) عينة وكذلك عينات من مياه الثرب (10)، وكانت نسبة العزل (27.77\%) من المجموع الكلي للعينات. توزعت بواقع (7) عزلات من الجروح، (13) عزلة من جهاز سحب السوائل من الجهاز التتفسي، (3) عزلات من الإدرار وعزلتان من مياه الثرب وكما موضح في

\begin{tabular}{|c|c|c|c|c|}
\hline المجموع الكلي للعزلات المئوية من & المجموع الكلي للعينات المئوية من & عدد العزلات & عدد العينات & مصدر عزل \\
\hline 52 & 14.44 & 13 & 30 & جهاز الـ \\
\hline 28 & 7.77 & 7 & 30 & الجروح \\
\hline 12 & 3.33 & 3 & 20 & الإدرار \\
\hline 8 & 2.22 & 2 & 10 & مياه الثرب \\
\hline 100 & $27.77 \approx$ & 25 & 90 & المجموع الكلى \\
\hline
\end{tabular}

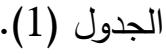

الجدول (1): اعداد ونسب عزلات جرثومة الزائفة الزنجارية المعزولة من مصادر مختلفة. 
كما يبين الجدول (1) ان عزلات جرثومة الزائفة الزنجارية المعزولة من جهاز سحب السوائل من الجهاز التنفسي شكلت اعلى نسبة بلغت (14.44\%) من المجموع الكلي للعينات و (52\%) من مجموع عزلات جرثومة الزائفة الزنجارية تليها عزلات الجروح بنسبة (7.77\%) من المجمع الكلي للعينات و(28\%) من مجموع عزلات هذه الجرثومة، ثم عزلات الإدرار وبنسبة (333\%) و (12\%) من مجموع العينات وعزلات هذه الجرثومة على التوالي، بينما كانت اقل نسبة عزل لهذه الجرثومة من عينات مياه الشرب وبنسبة (22.22\%) من المجموع العينات و (8\%) من مجموع العزلات والتي عُزلت بطريقة الترشيح الغشائي وكما موضح في الثكل (1).

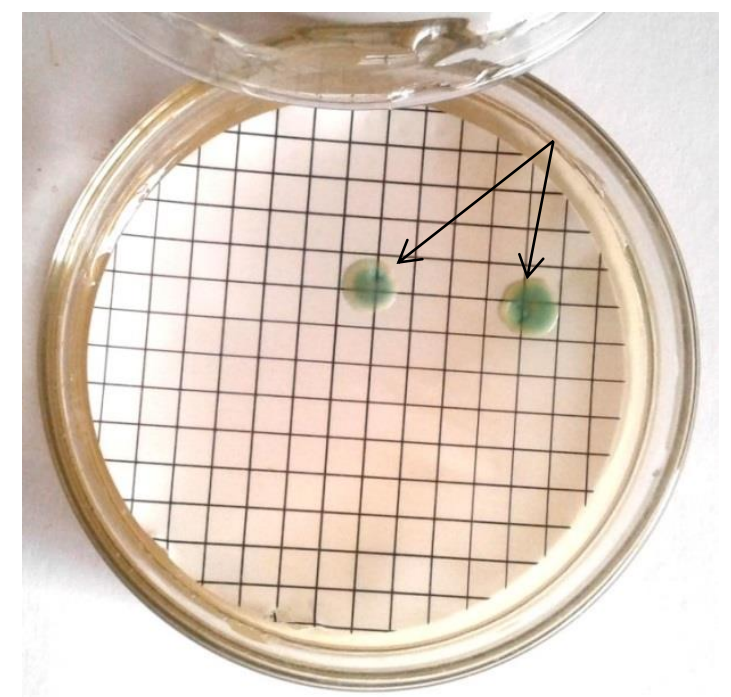

الثكل(1): مستعمرات جرثومة الزائفة الزنجارية المعزولة من مياه الثرب بطريقة الترشيح الغثائي. جاءت نسبة عزل جرثومة الزائفة الزنجارية من جهاز الـ Sucker لمجموع العزلات اعلى بكثير من النتائج التي حصلت عليها (14) إذ عزلت هذه الجرثومة من الجهاز نفسه في مستشفيات مدينة الموصل بنسبة (17.8\%) وكانت قد حصلت على (15) عزلة لجرثومة الزائفة الزنجارية من اصل (84) عزلة جرثومية مختلفة، وتُعد هذه النسبة مقاربة لنسبة عزل الجرثومة في الدراسة الحالية اذا ما قورنت بنسبة عزلها من المجموع الكلي للعينات. كما عزل (15) انواع مختلفة لجنس الزوائف .Pseudomonas spp من الجهاز نفسه في مستشفى ابن الاثير في مدينة الموصل وحصل على (8) عزلات جرثومية تعود لجنس الزوائف من اصل (30) عزلة جرثومية مختلفة وبنسبة (26.6\%) والتي تُشكل نصف النسبة التي تم الحصول عليها في هذه الدراسة، ونسبة اعلى اذا ماقورنت مع نسبة عزل الجرثومة من المجموع الكلي للعينات. اما دراسة (16) فقد أظهرت نسبة عزل لجرثومة الزائفة الزنجارية بلغت (39.28\%) من مجموع (140) عينة سريرية مختلفة، وبلغت نسبة عزل الجرثومة من الجروح (38.2\%) ومن الإدرار (25.5\%) وهى اعلى من النسب التي تم الحصول عليها في الدراسة الحالية لنفس مصادر العزل. واتفقت نتائج هذه الدراسة مع دراسة (17) إذ عزلت الجرثومة بنسبة (40.55\%) من مجموع (108) عينة سريرية مختلفة، وبلغت نسبة عزل الجرثومة من الجروح والإدرار (31.55\%) و (12.3\%) على التوالي وتُعد هذه النسب اعلى اذا ما قورنت بالنسب التي تم الحصول عليها في 
الدراسة الحالية من مجموع العينات. واتفقت نتائج الدراسة الحالية مع نتائج دراسة (18) فيما يخص نسبة عزل الجرثومة من الإدرار إذ كانت (12.24\%) فيما عزلها من الجروح وبنسبة (9.18\%) وذكر الباحث نفسه انه عزلها من مختلف مناطق الجسم بنسبة بلغت (67.32\%) من مجموع (98) عينة وهى نسب اعلى من نسب عزل الجرثومة من مجموع العينات في الدراسة الحالية، وكانت نسبة عزل جرثومة الزائفة الزنجارية من الجروح والادرار في الدراسة الحالية مقاربة لنتائج دراسة (19) الذان حصلا على (75) عزلة تعود لجرثومة الزائفة الزنجارية من اصل (100) عينة جُمعت من حالات مرضية مختلفة، وكانت نسبة عزل الجرثومة من الجروح (13.33\%) و (10.66\%) من الإدرار وهذه النسب اعلى اذا ما قورنت بالنسب التي تم الحصول عليها من مجموع العينات. وكانت نتائج هذه الدراسة مقاربة لنتائج دراسة (20) فيما يخص عزل الجرثومة من مياه الثرب إذ عُزلت هذه الجرثومة من مياه الشرب في محافظة نينوى بنسبة (5.2\%) وكانت قد حصلت على (7) عزلات تعود لهذه الجرثومة من بين (135) عزلة جرثومية مختلفة عزلتها من اصل (900) عينة لمياه الشرب. يعود سبب عزل جرثومة الزائفة الزنجارية بنسب عالية من أجهزة سحب السوائل من الجهاز التتفسي الى قلة العناية بهذه الاجهزة وعدم الادامة والغسل الدوري لها بسبب الظروف الحالية لمستشفيات الدحافظة وازدياد اعداد المراجعين وشحة المطهرات في هذه المستشفيات مما وفر ظروفاً ملائمة لنمو هذه الجرثومة، كما موضح في الشكل (2)، وان الاستعمال المتتالي للجهاز نفسه في سحب السوائل من الاشخاص المصابين باصابات مختلفة والاصحاء يُسهم في زيادة التلوث بهذه الجرثومة وانتشارها فقد اشار (21) الى ان تلوث جهاز الـ Sucker بجرثومة الزائفة الزنجارية يُعد احد اسباب انتشارها ونقل العدوى في بيئة المستشفيات. وتعود الإختلافات في نسب العزل للجرثومة نفسها من دراسة لأخرى حسب مصدر العزل، وتفاوت نسبة النظافة في المستشفيات، ونوعية مواد التعقيم والمطهرات المستعملة، كما وتعتمد على عدد العينات قيد الدراسة (22).

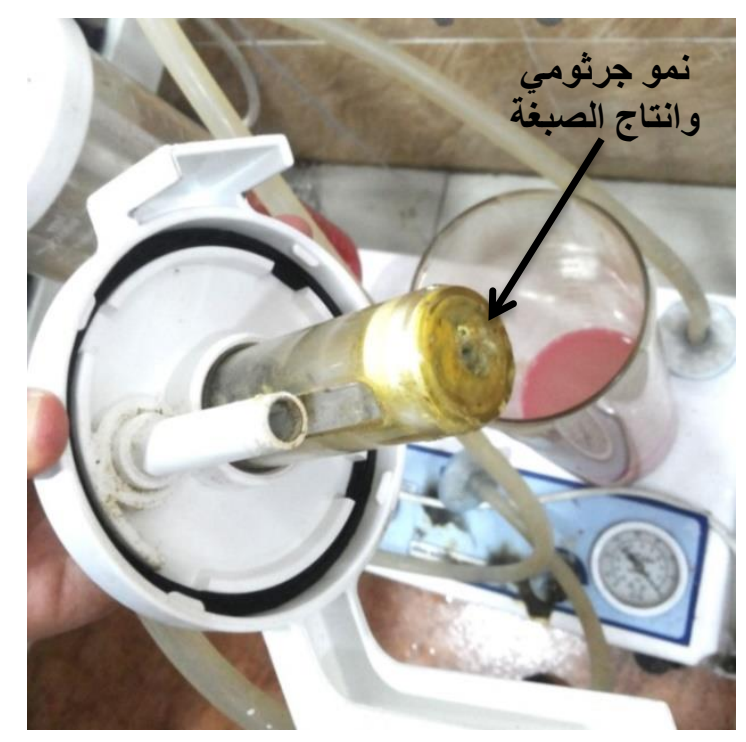

الثكل (2): احد اجهزة الـ Sucker الملوثة بانواع مختلفة من الجراثيم اهمها جرثومة الزائفة الزنجارية التي انتجت الصبغة في المنطقة المستعمرة. 
2- تثخيص جرثومة Pseudo.aeruginosa

شُخصت الجراثيم المعزولة اعتماداً على الصفات الزرعية، المجهرية والإختبارات الكيموحيوية المبينة في الجدول (2)، إذ ظهرت مستعمرات جرثومة الزائفة الزنجارية على وسط الآكار المغذي كبيرة لها مظهر مرتفع وحافات مسطحة، ورائحة تشبه رائحة العنب، اغلبها منتجة لصبغة البايوسيانين، وكانت المستعمرات شاحبة على وسط آكار الماكونكي لكونها غير مخمرة لسكر اللاكتوز وهذه النتائج جاءت متوافقة مع ماذكره (12)، كما ظهرت المستعمرات على وسط آكار الدم مخاطية محللة للدم تحللًا كاملاً م-hemolytic وهذا يتفق مع ما ذكره (9). وظهرت مستعمرات معظم العزلات على وسط آكار King A كبيرة قليلة التحدب ذات حافات مشرشرة King B مميزة نتيجةً لافرازها صبغة البايوسيانين، بينما ظهرت المستعمرات بلون اصفر لماع على وسط آكار نتيجةً لافراز صبغة البايوفردين الفلورسينية. كما نمت عزلات هذه الجرثومة على وسط آكار السترمايد الانتقائي الحاوي على مادة Cetrimide بنسبة (0.03\%) وهذه النسبة لاتؤثر على نمو جرثومة الزائفة الزنجارية ولكنها تُبطط نمو بقية الجراثيم. كما أظهرت النتائج قدرة جميع العزلات على النمو بدرجة حرارة (42)م وهي صفة تثخيصية مهمة للنوع Pseudo.aeruginosa عن بقية انواع الجنس Pseudomonas ولم تتمو جميع العزلات عند درجة حرارة (4)م، كما أظهرت جميع العزلات منطقة ضبابية منتشرة حول خط الطعن في الوسط شبه الصلب كدليل لقدرة الجرثومة على الحركة كما كانت جميع العزلات مميعة للجيلاتين عند نموها على وسط

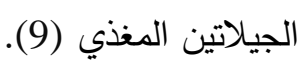

اما نتائج الفحص المجهري للمسحات الجرثومية المصبوغة بصبغة كرام فقد ظهرت خلايا هذه الجرثومة بشكل عصيات صغيرة سالبة لصبغة كرام وهذا يتفق مع ماذكره (10). تميزت جرثومة الزائفة الزنجارية بكونها موجبة لإختبار الاوكسيديز، إختبار الكتاليز وكذلك إختبار اليوريز. فيما كانت جميع العزلات سالبة لإختبارات؛ الاندول, المثيل الاحمر وفوكس بروسكاور، في حين ابدت جميع العزلات نتيجة موجبـة لإختبار استهلاك السترات الذي يُستعمل للتحري عن قابلية الجراثيم على استهلاك السترات كمصدر وحيد للكاربون. وعند تتمية العزلات على وسط آكار ثلاثي السكر والحديد (TSI) تبين ان جميع العزلات قيد الدراسة كانت غير مخمرة لاي نوع من انواع السكريات الثلاثة (كلوكوز - لاكتوز - سكروز) وغير مكونة لغاز (CO2) وغير منتجة لغاز كبريتيد الهيدروجين وهذا يتقق مع ماذكره (9). 
الجدول (2) : نتائج الإختبارات التشخيصية لجرثومة Pseudomonas aeruginosa.

\begin{tabular}{|c|c|c|}
\hline النتيجة & 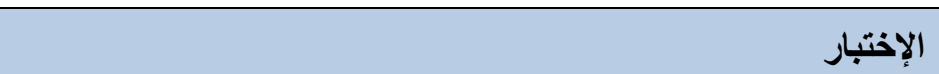 & ت \\
\hline- & استجابة الخلايا لصبغة كر ام & 1 \\
\hline 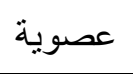 & شكل الخلايا على الثريحة & 2 \\
\hline+ & النمو على آكار ماكونكي & 3 \\
\hline+ & النمو على آكار السترمايد & 4 \\
\hline قاعدي & القعر & \\
\hline 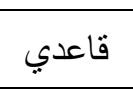 & TSI النمو على آكار & 5 \\
\hline- & ت تكوين غاز & \\
\hline- & إنتاج H & \\
\hline+ & 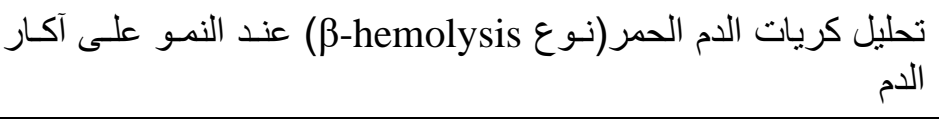 & 6 \\
\hline+ & الحركة في الوسط شبه الصلب & 7 \\
\hline+ & 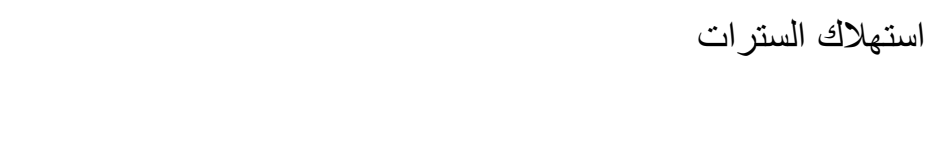 & 8 \\
\hline- & إختبار الاندول & 9 \\
\hline- & إختبار فوكس بروسكاور Vogas-proskauer & 10 \\
\hline- & إختبار المثيل الاحمر & 11 \\
\hline+ & انتاج انزيم الكتاليز & 12 \\
\hline+ & انتاج انزيم الاوكسيديز & 13 \\
\hline+ & انتاج انزيم اليوريز & 14 \\
\hline+ & انتاج انزيم الجيلاتينيز & 15 \\
\hline V & 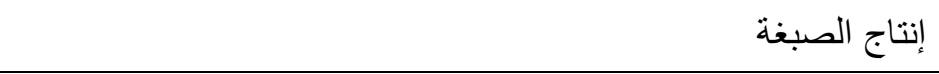 & 16 \\
\hline- & النمو عند درجة حرارة 4 م & 17 \\
\hline+ & النمو عند درجة حرارة 42 م & 18 \\
\hline \multicolumn{3}{|c|}{ + : نتيجة موجبة } \\
\hline
\end{tabular}


3- إنتاج صبغة البايوسيانين من قبل جرثومة الزائفة الزنجارية على الوسط الصلب

استُعمل وسط آكار King A لإختبار قدرة الجراثيم المعزولة على إنتاج صبغة البايوسيانين والذي يحتوي على املاح البوتاسيوم والمغنيسيوم بتراكيز كافية لتعزيز إنتاج هذه الصبغة من خلال دعم الجينات المشفرة لهاتيات

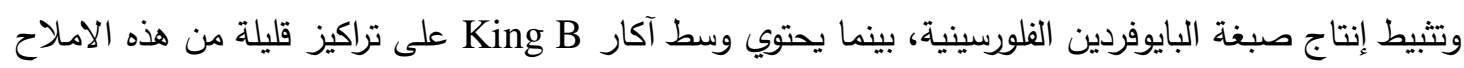
وتراكيز كافية من الفوسفات لتثبيط إنتاج صبغة البايوسيانين ودعم انتاج صبغة البايوفردين (23)، الثكل (3) (3)، إذ أظهرت توهجاً عند تعريضها للاشعة فوق البنفجية الثكل(4). وهذا يتفق مع ماورد في (9).
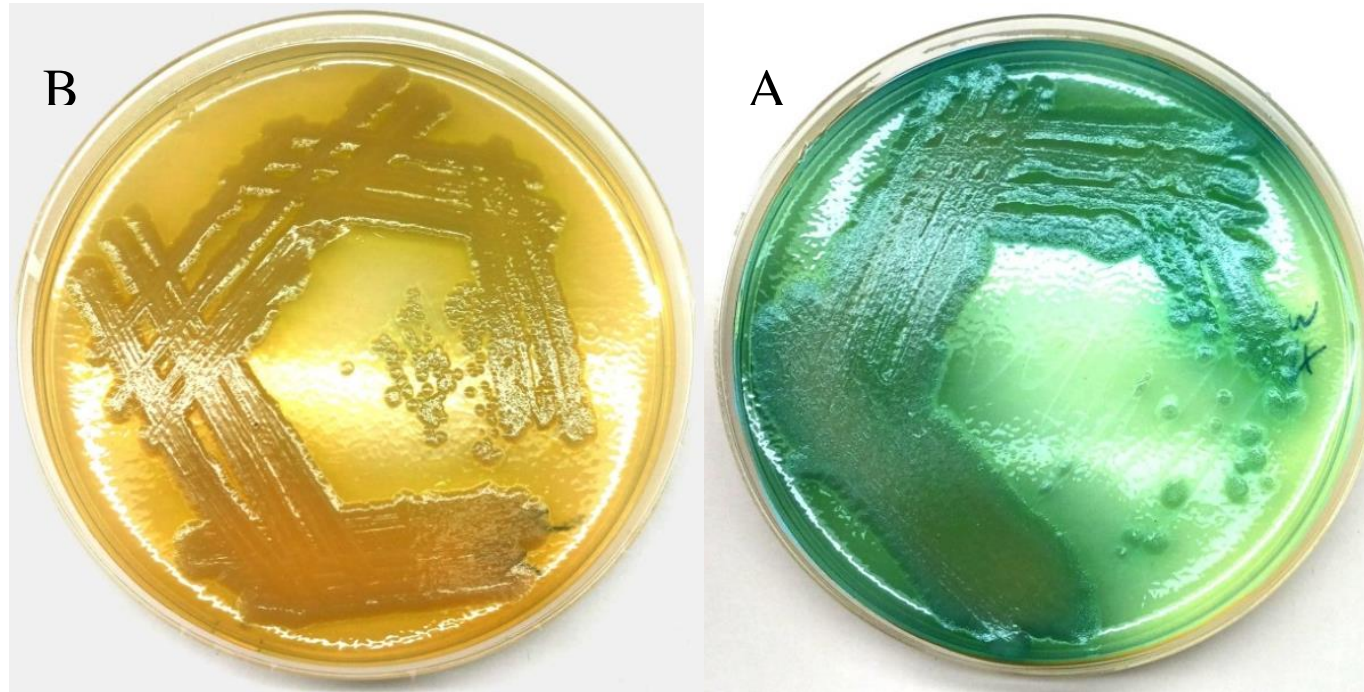

الثكل(3): A - إنتاج صبغة البايوسيانين من قبل جرثومة الزائفة الزنجارية على وسط King A. B تثبط إنتاج صبغة البايوسيانين على وسط King B

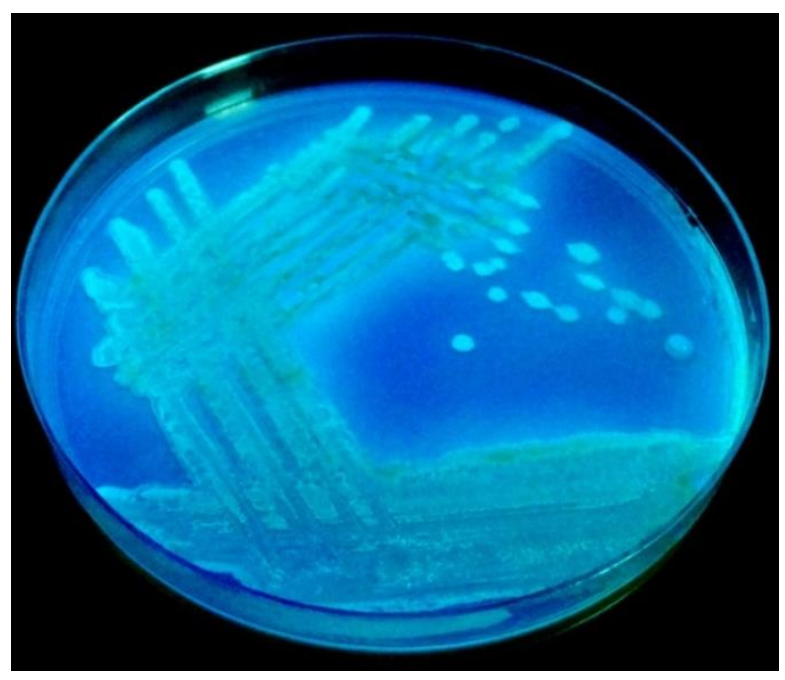

الثكل (4): توهج المستعمرات المنتجة لصبغة البايوفردين عند تعريضها للاثعة فوق البنفسجية. أظهرت النتائج ان (23) عزلة من بين (25) عزلة لجرثومة الزائفة الزنجارية كانت منتجة للصبغة الزرقاء المخضرة (البايوسيانين) على وسط آكار King A وبنسبة (92\%)، إذ انتجت جميع عزلات جرثومة الزائفة الزنجارية المعزولة من أجهزة الـ Sucker وكذلك المعزولة من الجروح صبغة البايوسيانين على هذا الوسط وبنسبة (56.5\%) و (30.4\%) على التوالي، وكانت عزلة واحدة من اصل عزلتين لهذه الجرثومة المعزولة من 
مياه الشرب منتجة للصبغة على هذا الوسط وبنسبة (4.4\%) من المجموع الكلي للعزلات، وكما مبين في الجدول (3)، جاءت هذه النتائج متفقـة مع (24) الذذي أثـار الى ان مابيـن (90-95\%) من عزلات جرثومة الزائفة الزنجارية تكون منتجة لصبغة البايوسيانين، وتطابقت نتائج هذه الدراسة مع نتائج دراسة (25) الذي وجد ان (45) عزلة من اصل (49) عزلة لجرثومة الزائفة الزنجارية كانت منتجة لصبغة البايوسيانين وبنسبة (92\%)، إذ ان (12) عزلة من اصل (13) عزلة من الجروح والحروق كانت منتجة لصبغة البايوسيانين، وكذلك (10) عزلات من اصل (11) عزلة من الإدرار اظهرت قدرة لانتاجها. كما اتفقت مع نتائج دراسة (18) التي وجدت ان (60) من اصل (66) عزلة لجرثومة الزائفة الزنجارية كانت منتجة لصبغة البايوسيانين وبنسبة (90.88\%)، وكانت جميع عزلات جرثومة الزائفة الزنجارية المعزولة من الجروح منتجة للصبغة، و (10) من اصل (12) عزلة لهذه الجرثومة المعزولة من الإدرار منتجة لها ـ

الجدول (3): اعداد ونسب عزلات جرثومة الزائفة الزنجارية المنتجة لصبغة البايوسيانين على وسط آكار .King A

\begin{tabular}{|c|c|c|c|}
\hline النسبة المئوية للعزلات & عدد العزلات المنتجة & عدد العزلات & مصدر العزل \\
\hline 56.5 & 13 & 13 & جهاز الـ Sucker \\
\hline 30.4 & 7 & 7 & الجروح \\
\hline 8.7 & 2 & 3 & الإلدرار \\
\hline 4.4 & 1 & 2 & مياه الشرب \\
\hline 100 & 23 & 25 & المجموع الكلي \\
\hline
\end{tabular}

4- قابلية جرثومة الزائفة الزنجارية على إنتاج انزيم البروتييز Protease عند تتمية العزلات الجرثومية على وسط آكار حليب الفرز اوضحت الدراسة الحالية قدرة جميع العزلات على إنتاج انزيم البروتييز Protease الذي يُعد احد عوامل الضراوة المهمة لهذه الجرثومة، وبنسبة (100\%) إذ أظهرت منطقة رائقة حول المستعمرات النامية نتيجة التحلل المائي للكازائين كدليل على إنتاج انزيم البروتييز، وقد اتقتت هذه النتائج مع دراسة (26) وكذلك مع دراسة (27) التي عزلت جرثومة الزائفة الزنجارية من مصادر مختلفة ووجدت ان جميع عزلات هذه الجرثومة منتجة لانزيم البروتييز وبنسبة (100\%). وأظهرت العزلات المنتجة لصبغة البايوسيانين انتشار الصبغة على هذا الوسط إذ يُعد من الاوساط المهمة لملاحظة انتاج الصبغات الجرثومية وجاءت هذه النتائج متفقة مع نتائج دراسة (25)، وكما مبين في الشكل (5). إذ يُعد هذا الانزيم احد عوامل الضراوة المهمة والمسؤول عن تحطيم الانسجة ونخر الجلد في الاصابات الجلدية ونزف الاعضاء الداخلية في الاصابات الجهازية (5). 


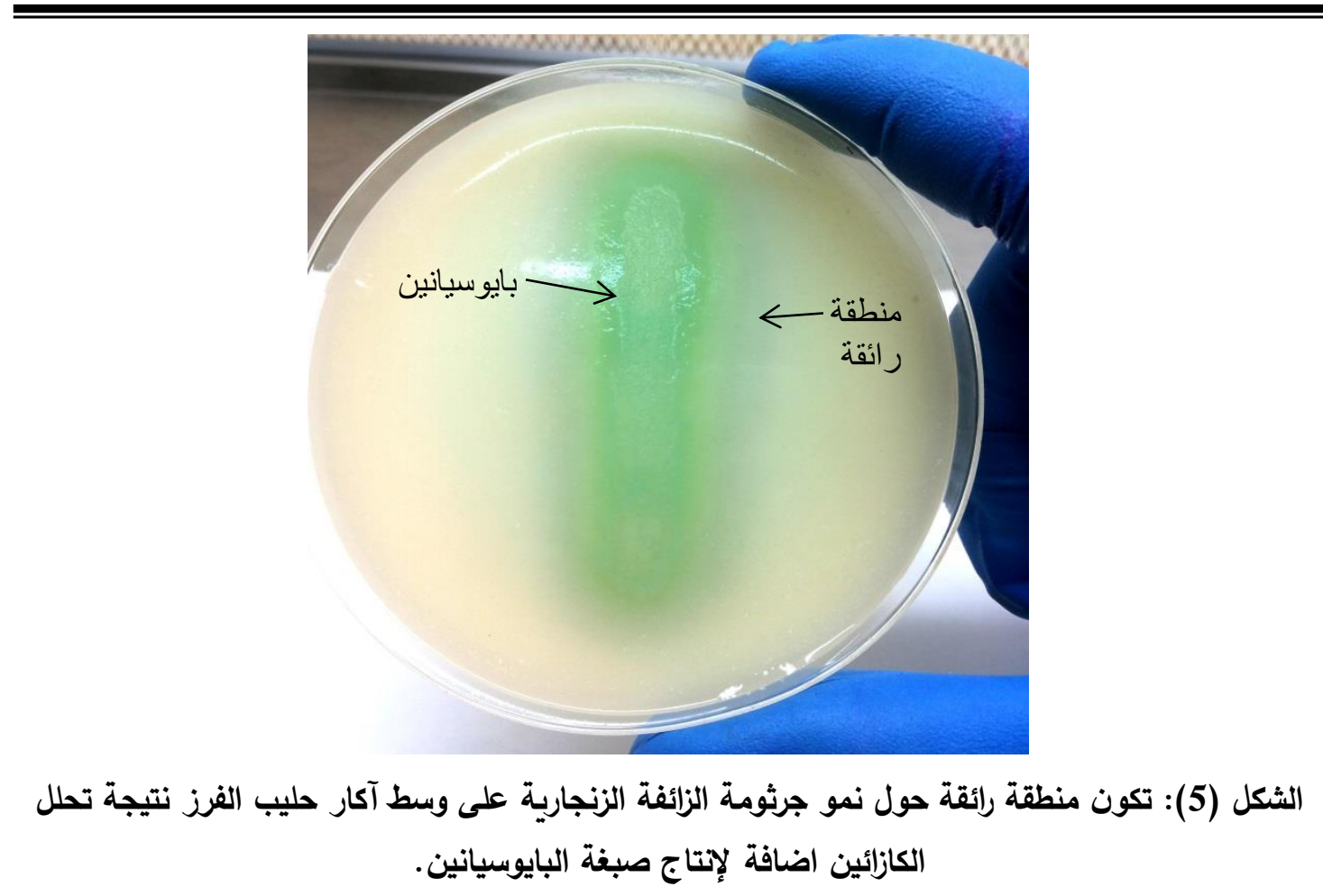

\section{References المصادر}

(1) Vessillier, S.; Delolne, F.; Bernillon J.; Saulueir, J. and Wallach, J. Euro. J. Bioch., 268 (4): 1049-1057 (2001).

(2) Streeter, K. and Katouli, M., Epidem. and Med., 2(1): 25-32 (2016).

(3) Zubair, M.; Malik, A.; Ahmad, J.; Rizvi, M.; Farooqui, K.; Rizvi M., J. of Biomd., 3(2): 147-157 (2011).

(4) Westman, E.L. ; Matewish, J.M. and Lam, J. S., Pathogenesis of bacterial infections in animals . Edited by Gyles, C.L. ; Prescott, J. F. ; Songer, J.G. and Thoen, C.O. $4^{\text {th }}$ ed., Jhonwiley and Sons, Inc., publication (2010).

(5) Wilson, R. and Dowling, R.B., Thorax, 53(3): 312-219 (1998).

(6) Brooks, G. F.; Carroll, K. C.; Butel, J.S. ; Mores, S. A., Jawetz Melnick and Adelberg's Medical Microbiology. $25^{\text {th }}$ ed. Lange, McGraw -Hill. USA (2010).

(7) Jayaseelan, S.; Ramaswamy, D. and Dharmaraj, S., World J. of Micro. and Biot., (304): 1159-68 (2014).

(8) APHA. American public health association., Standard methods for the examination of water and wastewater. American public health association, 20 ${ }^{\text {th }}$ ed., Washington D.C. , USA (1998).

(9) Procop, G.W.; Church, D.L.; Hall, G.S.; Janda,W.M.; Koneman, E.W.; Schreckenberger, P.C.; and Woods, G.L., Koneman's Color Atlas and Textbook of Diagnostic Microbiology. $7^{\text {th }}$ ed. Wolters Kluwer Health, Philadelphia (2017).

(10) Cappuccino, J. G., and Welsh, C. T., Microbiology: A Laboratory Manual. $11^{\text {th }}$ ed. Pearson Education. England (2018).

(11) Hassan, K. and Hussein T. A., Ira. J. of Sci., 4; 3203-5209 (2015). (In Arabic).

(12) Baron, E. J. ; Finegold, S. M. and Peterson, I. L. R., Bailey and Scotts Diagnostic Microbiology. $9^{\text {th }}$ ed. Mosby Company. Missouri (2007).

(13) Cruickshank , R . ; Marion , B . and Duguid, S., Medical Microbiology : The Practice of Medical Microbiology $.12^{\text {th }}$. ed. Churchill Livingstone, Edinburgh, UK. Vol 2 ( 1975 ).

(14) Al-Naemi N. A. F., M.Sc. Thesis, College of Science, University of Mosul (2001). (In Arabic).

(15) Al-Khaffaf, M. N. S. M.Sc. Thesis. College of Medicine. University of Al-Qadissiya (2012).

(16) Al-Damluji A. S. S., ph.D. Thesis, College of Science, University of Baghdad (2008). (In Arabic).

(17) Zeki, L. S., M.Sc. Thesis. College of Science. University of Baghdad (2009).

(18) Mohammed, H. A., M.Sc. Thesis. College of Science. University of Baghdad (2014). 
(19) Abdullah R. M. and Mehdi A. F., J. of Lif. Sci. Res. Cen., 10 (1): $45-49$ (2016). (In Arabic).

(20) Al-Oqaiday A. J. S.,M.Sc. Thesis, College of Science, University of Mosul (2009). (In Arabic).

(21) Mims, C.; Drockell , H. M.; Goering , R. V., Mims Medical Microbiology. $3^{\text {th }}$ ed., Elsevier Mosby, USA (2004).

(22) Livermore, D.M., Inter. J. of Antimicr. Agents, (3): 1-7 (2007).

(23) Ramalho, R.; Cunha, J.; Teixeira, P. and Gibbs, P.A., Microb. Meth., 49:69-74 (2002).

(24) Saha, S.; Thavasi, R.; and Jayalakshmi, S., Res. J. of Micro., 3(3), 122-128. (2008).

(25) Al-Imari, H.M.H., M.Sc. Thesis. College of Science. University of Baghdad (2011).

(26) Hoiby, N.; Johansen, H.K.; Moser, C.; Song, Z.; Ciofu, O. and Kharazmi, A., Micro. and Inf., (3): 2335 (2001).

(27) Al-Mashhadani K. A. M. ph.D. Thesis, College of Science, University of Mosul (2004). (In Arabic). 